\title{
Investigating Factors Based on an Extended UTAUT Model to Confirm Computer Science Instructors' Behavioural Intention to Adopt the Flipped Classroom
}

\author{
Eman M. Bakheet and Andrew M. Gravell
}

\begin{abstract}
In terms of technology used to improve education, the flipped classroom provides an opportunity to enhance the teaching experience for both learners and educators. Studies have shown that flipped classroom teaching has been widely adopted in computer science courses. However, the review conducted in this study of literature on flipped classroom practices in the context of computer science shows that the method has been investigated in relation to student perspectives, but also reveals a lack of research related to factors that could influence computer science instructors' intentions to adopt the technique.

Therefore, this paper presents and provides the preliminary results of an investigation of five proposed factors with flipped classroom practitioners who have applied the flipped classroom at least once in their teaching. A total of fourteen semi-structured interviews have been conducted with participants mainly from computer science and related disciplines, in order to confirm the significance of each proposed factor. The results provide evidence given by the participants on the significance of each of the five proposed factors, particularly the first three, as well as additional factors recommended by the respondents.
\end{abstract}

Index Terms-Computer science education, flipped classroom instructors' acceptance, instructors behavioral intention, UTAUT.

\section{INTRODUCTION}

With regard to merging technology with education, blended learning is a new direction of teaching and learning that has been adopted by numerous educational institutions. According to [1], digital technology plays a major role in the practices of higher educational institutions and has prompted a shift from traditional learning towards blended learning (BL). [1] defined BL as "approaches that allow students to engage with learning outside of the classroom with synchronous tools that afford, group chat, Skype communication and web conferencing or asynchronous tools such as discussion forums, blogs or social media networking scenario". According to [2] blended learning (BL) is a combination of e-learning teaching materials and face-to-face teaching. In addition, [3] stated that online and blended learning styles are accepted in educational institutions due to the availability of resources on the internet, which are

Manuscript received March 6, 2020; revised May 24, 2020.

Eman M. Bakheet was with Saudi Electronic University. She is now with School of Electronic and Computer Science, University of Southampton, Southampton, UK (e-mail: E.M.Bakheet@ soton.ac.uk).

Andrew M. Gravell is with School of Electronic and Computer Science, University of Southampton, Southampton, UK (e-mail: amg@ecs.soton.ac.uk). cheaper and more accessible than traditional resources.

Flipped classrooms (FC) are a method of blended learning. According to [2] "flipped or inverted classrooms are a blended learning modality, whereby traditional in-class lectures and homework exercises are reversed". The method was introduced by [4] as a student-centred approach in which learners explore learning materials through an online learning system and then attend offline flipped classes. Furthermore, [1] emphasized the importance of achieving a balance between face-to-face and online courses in a blended learning model in order to achieve the educational satisfaction of learners as well as educators.

The current paper is structured as follows: Section II discusses existing literature related to the flipped classroom and the Unified Theory of Acceptance and Use of Technology (UTAUT) model; Section III describes the research method and its process; Section IV discusses the results; Section V highlights the insights obtained from the results and additional factors proposed by the participants; Section VI presents the conclusion and recommendations for future research; and finally Section VII presents the limitations.

\section{LITERATURE REVIEW}

This section is divided into two main parts. The first part presents a review of existing studies related to the flipped classroom in the context of computer science education. Then, the second part provides insights into the use of the Unified Theory of Acceptance and Use of Technology (UTAUT) model in educational studies and its influencing factors.

\section{A. Flipped Classroom}

Previous research regarding the flipped classroom has tended not to investigate factors that prompt computer science instructors to adopt the method in their teaching. The following section provides insight into some of the issues discussed in the existing literature.

Research has shown that acceptance of the flipped classroom among educators and researchers is varied. Some practitioners have endorsed the potential for the flipped classroom to aid the learning experience, but others have argued that it is not ideal and is no different from a traditional classroom. The flipped classroom method has been introduced in different majors, such as computer science, mathematics, physics, English, and statistics, and other educators have also expressed interest in switching to this new approach. Since the current study is focused on computer science education, the following literature review 
is related to investigations of the flipped classroom in that context. A systematic review conducted by [5] illustrated the increasing interest in the flipped/inverted classroom teaching approach, whereby the authors observed a significant increase in the amount of research papers on flipped classrooms published in 2012, 2013, and 2014 in comparison with previous years. They also noted that the majority of the studies published focused on computer science/information technology courses.

With regard to computer science teaching, [6] argued that programming instruction requires an active learning environment as well as collaborative learning, which leads to the use of the flipped classroom during in-class activities. In addition, [7] investigated the application of the inverted classroom in computing courses by showing how different courses from software engineering were tested. They also highlighted the importance of gaining acceptance from both instructors and learners regarding the inverted models in order to obtain the expected results.

\section{B. Unified Theory of Acceptance and Use of Technology (UTAUT)}

The review of the literature in terms of technology acceptance models, reveals that UTAUT model has been used in investigating individual acceptance of technology in E-learning related studies ([8]-[13] and [14]). Indeed, [15] explained that their study aimed to compare between eights significant models to understand the individual acceptance and intention to use technology in organizations, combine them, and unify them into one model, UTAUT.

In previous related work [13] explained the suitability of UTAUT model in related studies where technology employed in education by reviewing 11 studies. [13] proposed to initiate the investigating of the factors with the practitioners' by proposing five main factors as an extended model based on UTAUT which are: performance expectancy, effort expectancy, social influence, facilitating condition, and technology self-efficacy.

In terms of comparing between UTAUT and other models, [15] in their study confirm the strength of the UTAUT model over the other compared model as they stated "UTAUT was able to account for 70 percent of the variance in usage intention a substantial improvement over any of the original eight models and their extensions". Additionally, in terms of the UTAUT model appropriateness, [14] stated that "proven to better explain the variance on usage intention than previous acceptance model". Additionally, [12] and [16] confirmed as mentioned before that UTAUT overcomes the compared models. Indeed, [12] clarified that the UTAUT provide a complete insight into the individual acceptance of the technology more than the other models. Whereas, [16] clarified that the UTAUT model was one of the four used models in understanding and predicting an individual adoption and usage behavior.

\section{RESEARCH METHOD}

At this stage of the study, the researcher sought to obtain an in-depth understanding of the adoption of the flipped classroom method and its related factors and moderators from the perspective of its practitioners. Purposeful sampling was used to generate the qualitative sample, following concept sampling and snowball sampling strategies. According to Creswell, [17] (p. 228) "In purposeful sampling, researchers intentionally select individuals and sites to learn or understand the central phenomenon". In addition, Creswell, [17] (p. 230) described the concept sampling as " $a$ purposeful sampling strategy in which the researcher samples individuals or sites because they can help the researcher generate or discover a theory or specific concepts within the theory" and snowball sampling as another strategy that researchers can use, whereby participants are asked to suggest other participants who could take part in the research.

\section{A. Interview Process}

In this study and at this stage, forty-three flipped classroom practitioners in Computer Science (CS) and Science, Technology, Engineering, and Mathematics (STEM) fields were targeted to gain insights regarding their experience in applying the flipped classroom method in their teaching, as well as to explore factors and moderators that influenced their adoption of the flipped classroom, fourteen agree to take part of the study. First, the researcher selected practitioners in computer science and STEM fields using their published studies and reports on their flipped classroom experience. An email was sent to invite them to be part of the study, and once they had agreed to participate, they were sent a participant information sheet and consent form and asked to set-up a suitable day/time to conduct the semi-structured interview.

\section{B. Method to Analyze the Collected Data}

According to Creswell, [17] (p. 262), the amount of data collected from interviews could be unexpected for new researchers in qualitative research, as it is often vast; thus, these data should be organized in a way that helps the researcher. Creswell, [17] provided examples of effective organization processes, such as "developing a matrix or a table of sources that can be used to help organize the materials".

Furthermore, in terms of dealing with qualitative information and using thematic analysis, they claimed that "It is the first qualitative method of analysis that researchers should learn as it provides core skills that will be useful for conducting many other forms of qualitative analysis" Braun and Clarke [18].

\section{Participants Demographic Information}

TABLE I: FLIPPED CLASSROOM PARTICIPANTS FROM 1 TO 14

\begin{tabular}{|c|c|c|}
\hline FC-P\# & Gender & Course Area \\
\hline FC-P1 & M & CS \\
\hline FC-P2 & M & Medicine \\
\hline FC-P3 & M & CS \\
\hline FC-P4 & F & CS \\
\hline FC-P5 & M & CS \\
\hline FC-P6 & M & CS \\
\hline FC-P7 & F & CS \\
\hline FC-P8 & F & CS \\
\hline FC-P9 & M & Educational IT \\
\hline FC-P10 & F & CS \\
\hline FC-P11 & M & Mathematics \\
\hline FC-P12 & M & CS \\
\hline FC-P13 & M & F \\
\hline FC-P14 & &
\end{tabular}

This study was conducted with 14 participants from computer science and STEM fields who had applied the 
flipped classroom at least once. To clarify, all practitioners had applied a fully-flipped classroom in their courses except 2 participants. FC-P12 had used a partially-flipped style, FC-P11 had one of the flipped courses in a partially-flipped style. More demographic information for the participants is presented in Table I.

\section{RESULTS}

This section discusses the result of validating and confirming five main factors with the flipped classroom practitioners. After discussing each proposed factor in section two of the interview, the participants were then asked to rate the proposed factors from their perspective, using 5-point Likert scale questions, to confirm the value of each factor.

In the following sub-sections, the results for each factor and the sub-themes related to it are analyzed according to the participants' responses. The factor results are presented in the following order: performance expectancy, effort expectancy, social influence, facilitating condition, and technology self-efficacy.

\section{A. Performance Expectancy $(P E)$}

"The degree to which an individual believes that using the system will help him or her to attain gains in job performance" Venkatesh et al. [15] (p. 447).

The results presented in Table II reveal a strong agreement regarding the significant role of $\mathrm{PE}$ as a factor that influenced the instructors' intentions to adopt the flipped classroom. Overall, 11 participants out of 14 expressed agreement with the importance of this factor. Indeed, FC-P10 commented: "I think that's performance expectancy, that's the most important one."

TABLE II: FLIPPED CLASSROOM PRACTITIONERS’ RESPONSES ON THE VALUE OF PE ON THE INSTRUCTORS' BEHAVIORAL INTENTION

\begin{tabular}{|l|l|l|l|l|}
\hline Highly agree & Agree & Neutral & Disagree & Highly disagree \\
\hline 8 & 3 & 2 & 0 & 0 \\
\hline
\end{tabular}

\section{1) Better teaching experience}

Related to performance expectancy, participants were also asked whether the flipped classroom provided a better teaching experience than the traditional one. Overall, their responses were positive, where practitioners had provided opinions from different points of views in their teaching experience or where they felt flipped classroom could enhance their teaching experience.

It is interesting that FC-P1 highlighted the role of course content. Although they agreed that the flipped classroom delivered a better teaching experience, they also stated that "but there might be a course where for some reason content is better delivered in a traditional style, I guess". In addition, a frequent comment made by respondents was that advance preparation benefitted programming students. For example, FC-P4 highlighted: “...the course type, if it's programming, yes. It is beneficial for students to prepare for the material in advance." FC-P2 also highlighted the importance of preparation, explaining how it was "beneficial for my students, students well prepared, and update their knowledge”. FC-P5 added that “...better learning of theory in advance to the classes at least the student should be better equipped to do the actual exercises in class".

FC-P3, FC-P5, FC-P6, and FC-P11 all stated that the flipped classroom helped to create an active learning environment. According to FC-P3, the method fostered "more active learning" and helped teachers "focus specifically on the areas where students have questions rather than having to give a sort of a generic lecture”. FC-P5 noted that the method "gave us much more time for active learning”. FC-P11 also stated that it enhanced interactivity: "we've got more time to do proper interactive teaching in the face to face sessions".

FC-P2, FC-P7, FC-P11, FC-P12 and FC-P13 commented on the contribution of the flipped classroom to enhancing learners' knowledge. FC-P7 stated that "learners in the flipped classroom can create more new knowledge from the original knowledge transferred by instructors". In addition, FC-P11 described how it facilitated "better learning, students are asking better questions, And that's always a good sign for learning”. With regard to helping students who struggled with the material by offering extra (optional) help in the extra sessions, FC-P12 observed: "I think it was quite helpful, the session that we ran, and it's encouraging the students to ask all kinds of questions. I think that creates an environment where you've got more support and also you're really saying, when you're lecturing yourself, you know you always ask yourself 'Well, is this a good use of my time?'”

FC-P6, FC-P8, FC-P9, and FC-P10 highlighted the value of the flipped classroom in facilitating engagement with the students to create a better teaching experience. FC-P6 commented on the benefits of better student engagement with the material: "They can't be...they can't sit in the classroom and be a passive listener. So in this way it engages them more". In addition, FC-P8 stated: "I believe that the flipped classroom approach allows the instructor more time to actually work with students on applying and understanding how to apply the knowledge that they have”. FC-P9 also highlighted how the method was beneficial because the students were "by spending more time in class on discussion and less on lectures". FC-P10 explained the value of allowing the students to express and be an active member of the class rather than sitting passively: "For me it's a better experience. gives me the opportunity to listen to the student stories. I watched their performance, so that gave me a better teaching experience."

Interestingly, FC-P6 highlighted the "better teaching experience for non-English speakers"; that is, they argued that the flipped classroom created a better teaching experience for overcoming the language barriers issue.

2) Can Flipped Classroom Enhancing instructors' productivity and academic performance?

The responses given by practitioners in relation to this factor varied. Some agreed, some were neutral, and others disagreed.

FC-Ps 2, 3, 4, 6, 7, 8, 11, 10, 12, 13, and 14 agreed that the flipped classroom could enhance the productivity and/or the academic performance of the instructors. FC-P6 commented: "It would help free up more time after the initial time that it took to actually do that, to put together the flipped classroom materials". FC-P12 added: "You know revise your 
knowledge about it and then you're able to explain it to them. So definitely, I think that if I'm using a flipped classroom practical aspects to the teaching, definitely you know this is something that can improve job performance." However, FC-Ps 1 and 8 disagreed that the flipped classroom enhanced their productivity and/or academic performance. Indeed, FC-P8 explained that "It's not just providing a link to a paper or telling people to watch a video of a lecture that is being recorded that takes, you know, maybe whole hours of lecture you have to give the information in a vitally clever way and that takes more time. So I guess it can actually have a negative effect on productivity in that sense".

\section{B. Effort Expectancy (EE)}

"The degree of ease associated with the use of the system" Venkatesh et al. [15] (p. 450).

The results presented in Table III show a strong agreement regarding the significant role of $\mathrm{EE}$ as a factor that influenced the instructors' intentions to adopt the flipped classroom. Indeed, 13 participants out of 14 agreed with the importance of this factor. Although 1 participant (FC-P7) strongly disagreed with this factor, stating: "It's difficult to provide learning materials for learner to study in advance before class.". However, one of the participants who was highly agree with this factor, (FC-P14) commented "the effort expectancy I think the highest, so yes I highly agree, that is the main thing that puts people off doing it or not".

TABLE III: FLIPPED CLASSROOM PRACTITIONERS' RESPONSES ON THE VALUE OF EE ON THE INSTRUCTORS' BEHAVIORAL INTENTION

\begin{tabular}{|l|l|l|l|l|}
\hline Highly agree & Agree & Neutral & Disagree & Highly disagree \\
\hline 5 & 8 & 0 & 0 & 1 \\
\hline
\end{tabular}

1) Decreasing the amount of effort required for educational process

First, 7 participants agreed with the statement that applying the flipped classroom reduced the amount of effort required. FC-Ps 1, 3, 4, 6 and 14 highlighted that it generated long-term benefits by reducing the amount of effort required in subsequent semesters. For example, FC-P1 stated: "In the long term, like I said, once the course is established and you've taught it a couple of times, then (that effort pays off)." Additionally, FC-Ps 2, 5, and 9 agreed that it reduced effort in terms of in-class activities/meetings.

Second, 9 participants (FC-Ps 1, 3, 5, 7, 8, 9, 10, 11, and 13) disagreed with the statement that applying the flipped classroom reduced the amount of effort required either in class, outside class, or regarding the preparation of materials. However, although they argued that the effort they made did not decrease, FC-Ps 5, 8, and 11 believed that the effort was worth it. For example, FC-P8 stated: "So I wouldn't say necessarily that it's less effort to teach in the flipped classroom, but maybe that the gains are worth it".

Third, 6 participants (FC-Ps 4, 5, 9, 10, 12, and 13) were neutral regarding the statement that applying the flipped classroom reduced the amount of effort required for preparing exams/tests/homework. For example, FC-P12 stated that "I think in general people would probably see that you know provided the instructor who obviously knew the material very well. (We take that as a known), So they didn't have to go away and fully understand, you know revise their knowledge and make sure they understand all the details of it, even if it's in there. then I would have thought that it should reduce the effort".

2) Monitoring out-of-class activities through the learning management systems

In terms of exploring the effort required for monitoring the students' out-of-class activities through the learning management system, responses from participants varied. Some found it valuable, some had used it but did not consider it valuable, some preferred to do the observation by themselves, using quizzes related to the videos that the students watched, and students' activity in labs, the pre-homework answers, and completion of the handouts. Other respondents believed that it required extra effort from instructors, and some believed that the results they got from the learning management system did not represent the students' real activities accurately. However, it was interesting that 1 of the participants was seeking a kind of method or way to check if the students really watched the material/the summary posted.

The following are some responses from participants collected into groups based on the similarity of the feedback

Is it necessary/unnecessary?

FC-P1 commented: "I don't think it's completely necessary". Whereas FC-P10 stated: "That is necessary, that is necessary, because some students just watch the videos and maybe they are not. So I must give them some assignments". Is it easier/harder?

FC-Ps 3, 5, 7, 8, and 10 agreed that it is easier. FC-P3: commented: "But at least in the learning management system that I have used (it's not particularly hard or time consuming) to look at what the students are doing", and FC-P5 claimed: "It would be easier for sure to track their activities through learning management system. A good LMS can give a summary to determine how many students have access to materials." FC-P7 also agreed: "It's easier because LMS can help to monitor the students' out-of-class activities, but it is not mean that the flipped classroom learning can reduce the instructor's effort." Due to their previous experience in employing analytics to track student performance, FC-P8 stated: "I think it's a natural thing for me to want to do, of course it is easier for me." Finally, FC-P10 added: "In our LMS we have, we can get the data about the numbers of the post and the time they finish the quizzes. It's easy to monitor the students' learning performance. For me that is a way to encourage the students to watch the videos to learn."

\section{Instructor observation}

FC-Ps 3, 4, 11, 12, and 13 commented on the types of instructor observation carried out in the classroom, such as labs and quizzes. According to FC-P3, "they are doing these little activities in class. We're talking about them, and you just sort of, through that interaction that I have with them, I think that's where I get the best sense of certainly how effectively they've used the out-of-class materials." FC-P12 added: "Yeah I think definitely this, you know the instructor has some better observation of what's going on." In addition, FC-P11 described "using handouts as a method to monitor if students watched the materials or not by answering the questions on the handout and do the checking at the beginning of the lecture". 


\section{Social Influence (SI)}

"The degree to which an individual perceive that important others believe he or she should use the system." Venkatesh et al. [15] (p. 451).

The results presented in Table IV show a strong agreement between participants regarding the significant role of SI as a factor that influenced instructors' intentions to adopt the flipped classroom. Indeed, 11 participants out of 14 agreed with the importance of this factor. FC-P6 explained why they perceived this factor to be important: "Because if you don't have support or if you don't have perceived to support a precision support then the motivation to do this just wouldn't be there." However, FC-P4 disagreed with the notion that SI has an influence on intentions, arguing that "we are not influenced by the important people in the department in the way of teaching."

TABLE IV: FLIPPED CLASSROOM PRACTITIONERS' RESPONSES ON THE VALUE OF SI ON THE INSTRUCTORS' BEHAVIORAL INTENTION

\begin{tabular}{|l|l|l|l|l|}
\hline Highly agree & Agree & Neutral & Disagree & Highly disagree \\
\hline 3 & 8 & 1 & 1 & 0 \\
\hline
\end{tabular}

\section{1) Reasons for implementing the flipped classroom}

The participants identified several reasons for implementing the flipped classroom.

- FC-Ps 1, 2, 5, 10, 8, 13 and 14 were having mutual personal beliefs or personal interests in this model, that in terms of improving the learning.

- Whereas FC-Ps 1, 3, 11, and 12 stated that the flipped classroom was an effective learning method for students in terms of improved interactivity, and creativity.

- In addition, FC-P4 stated that it was a way to help students (non-native English speakers) to overcome language barriers, and to help students at basic levels to engage more with the material by re-watching it as much as they want.

- FC-Ps 2, 5, 7, 10, 8, and 13 spoke about receiving support from their university/college/school in terms of funding or training.

- Additionally, FC-Ps 4 and 6 agreed that the flipped classroom was useful for managing large classes.

- In addition, FC-P7 observed that the method was suitable for this particular course.

- Finally, FC-Ps 7 and 9 stated that they were open to trying new teaching methods.

\section{2) First adopter of the flipped classroom}

The participants were also asked whether their previous colleagues had influenced their attitude to adopting the teaching model in their courses. Specifically, the respondents were asked whether they were the first to adopt the flipped classroom in their course and if there were others who employed it.

The responses can be classified into two categories. Firstly, the participants who were the first/only adopters of the flipped classroom (FC-Ps 1, 2, 3, 5, 6, and 9). FC-P1 stated "I'm the only one who does that." FC-P1 clarified that "other professors are using different active learning techniques but not flipped classroom." FC-P3 described how they were the "first one to apply it in the department. There are other people in this department who teach in a flip style, but I think they've adopted it kind of independently."

The second category is the participants who noted that the flipped classroom had been adopted by other colleagues prior to them (FC-Ps 3, 4, 7, 8, 10, 11, 12, 13 and 14). According to FC-P7, "There are many lecturers use the flipped classroom in my university, including some lecturer in my department." Additionally, FC-P8 noted that it was quite popular in their institution: "No there are other people using it. So it's not everybody but there are few, particular in software engineering". Added, "I only know that we probably have a greater than average amount of people doing it than maybe other universities. It seems to be quite popular here". Finally, FC-P10 stated that at least one instructor at each school applied the method, explaining that they were "not the only one, some others, many others use it." Furthermore, that it was "not very common, maybe about $20 \%$ or $10 \%$, but in every school we have at least one".

\section{Facilitating Condition (FC)}

"The degree to which an individual believes that an organizational and technical infrastructure exists to support use of the system." Venkatesh et al. [15] (p. 451).

The results in Table $\mathrm{V}$ reveal that respondents generally agreed that FC was a significant factor that influenced instructors' intentions to adopt the flipped classroom. Indeed, 8 participants out of 14 expressed their agreement regarding the importance of this factor. Two participants disagreed with this notion. Of the respondents that agreed, FC-P-6 explained that "I think sometimes again people who are kind of starting out doing this thing may not know entirely what they need, but I think as long as they think it's possible that they may be OK with that to go forward." Of the participants who disagreed, FC-P-2 clarified that "have nothing to do with me and my students when I'm dealing with them in terms of the flipped classroom”.

TABLE V: FLIPPED CLASSROOM PRACTITIONERS' RESPONSES ON THE

VALUE OF FC ON THE INSTRUCTORS' BEHAVIORAL INTENTION

\begin{tabular}{|l|l|l|l|l|}
\hline Highly agree & Agree & Neutral & Disagree & Highly disagree \\
\hline 1 & 7 & 3 & 2 & 0 \\
\hline
\end{tabular}

\section{1) University management and IT support}

With regard to university management support, participants generally stated that they received support from the management in different ways. Some described receiving encouragement through a culture of support, others described the availability of funding/grants, training/workshops, and teaching methodologies, whereas others stated that the classroom technology infrastructure was significant. The following are some responses that illustrate the different perspectives of the participants.

FC-Ps 1, 7, 13, and 5 talked about the availability of grants/funding and training/workshops. According to FC-P1, "they're willing to provide general support like funding support or, you know, some sort of grant to cover the time that it takes or whenever to do this". FC-P13 and FC-P7 made similar comments, that they were supported by training or workshops in addition to funding. FC-P13 explained: "They offer (usually there's some money involved), if you sign up for a workshop like that you may get (500 dollars)."

Additionally, FC-P7 clarified that the Innovation Learning Center provided training courses in addition to funding: 
"Learning Innovation Center, provides support funds and training courses". Furthermore, 2 participants explained that they received support through instructional design: FC-P3 said, "we have our IT department, does extend to include things like (instructional design) as well as just kind of straight hardware and software support" and FC-P13 stated "we have what we called distance learning, and I was assigned a person there. She was like my help, I could always call her and meet with her, and setting things up from the IT part was there. She actually is not just an IT person, but she also has training in teaching aspect this methodology".

In terms of IT support, FC-Ps 1, 3, 5, 8, 10, and 11 agreed that they received support for learning management systems in general but not specifically for the flipped classroom.

However, some participants commented on the lack of support they received regarding recording video materials. Indeed, the comments show that they this was carried out independently by the instructors and sometimes with the help of students. FC-Ps 1, 4, 6, 9, 10 and 14 emphasized that they worked independently to create the videos and that they did so without IT support. According to FC-P1, "I made all my own lecture videos, I pretty much did everything myself. You know, like, so for example the scripts that I mentioned to keep track of students, when they view the videos on the learning management system. That was not something that, like, there was anyone in the IT department that could help me with that". In addition, FC-P4 clarified: "because I think we independently organized this WordPress website, we even bought server, and domain to support all those things and the materials are also made by professors individually with no help. So I think it's all made by all the faculties and members of the computer science department themselves."

\section{E. Technology Self-Efficacy (TSEF)}

Long et al. [11] defined technology self-efficacy as "an instructor's belief that s/he can use the instructional technology to improve students' learning experiences".

The results in Table VI show an agreement among participants regarding the role of TSEF as a factor that influenced instructors' intentions to adopt the flipped classroom. Indeed, 9 participants out of 14 agreed that it was an important factor, and only 1 strongly disagreed. FC-P8 strongly agreed that it was valuable, and commented: "I think this probably has quite an impact on the instructor, because if you don't have confidence in using these technologies and online technologies can be hard to use as well, if you feel like you're losing track of the students and you don't have confidence in understanding what they're doing or how you would get the understanding of what they're doing.". However, (FC-P14) was highly disagree with this factor, stated that "that's not the thing that pulls them off. They would not say I can't do it. They would probably say I can do it even if they can't. Again in the context of computer science They're probably considered themselves Sufficiently competent for that, or that's not the thing that's going to be a barrier for them".

TABLE VI: FLIPPED CLASSROOM PRACTITIONERS' RESPONSES ON THE VALUE OF TSEF ON THE INSTRUCTORS' BEHAVIORAL INTENTION

\begin{tabular}{|l|l|l|l|l|}
\hline Highly agree & Agree & Neutral & Disagree & Highly disagree \\
\hline 4 & 5 & 3 & 0 & 1 \\
\hline
\end{tabular}

1) Instructor's confidence in using technology effectively

The majority of responses demonstrated the participants' beliefs that they were confident in using technology in their courses. Indeed, FC-Ps 2, 3, 5, 7, 8, 9, 10, 11, 12, 13 and 14 strongly agreed that they had the confidence to use technology effectively in their role as instructors, whereas FC-Ps 1, 4, and 6 were more neutral in their responses.

Overall, the responses illustrated different perspectives. Some participants commented that their confidence was attained through their academic majors and their experience in using technology to create and edit videos and so on.

FC-P9, FC-P1, and FC-P10 believed that their confidence was driven by their teaching experience in computer science or instructional technology. FC-P9 stated: "Yes, as a computer science teacher I am comfortable with the technologies." FC-P1 added: "generally I had a feeling that this is all stuff which I could handle, like I had not necessarily done a lot of video editing or recording before or screen casting, but I had a sense that I could manage it. And in general, you know, just being in computer science and being able to code software". In addition, FC-P10 said: "I think so, I am confident, my major was in instructional technology, of course, I know how to make the videos, and I know how to use the equipment in a classroom. So I think it's effective." However, in terms of the perspective of computer science instructors compared with teachers of unrelated disciplines, FC-P5 commented that computer science teachers might be more open to adopting these kind of approaches in their teaching practice: "I discussed with, like, for example, business science professor or humanities professor, it appears to me that computer science teacher is more, at least, familiar with web technologies".

On the other hand, FC-Ps 8, 3, 5, and 11 believed that their confidence was driven by their previous experience in dealing with technology. FC-P8 explained that they gained confidence through previous work teaching online courses and receiving training in using these approaches, "so I feel that it just comes from a place of knowledge”. Furthermore, FC-P5 stated: "I have a strong experience in technology needed to deliver such materials. In addition to that, during my undergraduate studies I used to work in technical support; it's not related to my current profession, but I'm really proficient in solving technical problems".

2) The role of technology self-efficacy in the student learning experience

The majority of the respondents agreed that TSEF could play a role in enhancing the student learning experience. Six practitioners (FC-Ps 2, 5, 7, 8, 10 and 14) expressed strong agreement with this notion, and 6 practitioners (FC-Ps 1, 3, 9, 11,12 , and 13) gave neutral responses.

Of the respondents who strongly agreed, FC-P8 said: "Yes, definitely. So I think that's very important. Because we're expecting them to direct, in a way, some of their own learning and expecting them to direct their own learning, So I think the student does have to have some confidence and some technology self-efficacy to be able to engage fully and learn in this way." Meanwhile, FC-P10 described the role of TSEF in different majors: "Yes, in my course, the students from the science majors like physics and chemistry, they always use lots of software, they have high TSEF, they are confident 
because they know how to make the video products to show themselves. But the students from Chinese literature history, their technical skills are relatively not very good, some of them are afraid that they cannot do well in the presentations, in making the product; yes, for the students it matters."

Of the participants who gave neutral responses, FC-P1 said: "Yes, I think so, I think again in a computer science course, especially, like, students, they want to have a sense that the instructor knows what they are doing," and FC-P3 added "Yes, I think so. Because a lot of the flipping of the classroom is done through technology, through LMS, and so the students certainly have to believe that they are able to use that technology." Finally, FC-P9 stated that students need to know the fundamentals or the basics in order to deal with the materials: "As long as students are comfortable using web browsers, watching videos on the web - that is all they need."

\section{Insight InTO AdDitional Proposed FACtors}

During the process of confirming and validating the five proposed factors with the participants, they were also asked if they could identify other factors that should be included, and additional factors were recommended by some participants. These are: communication between students themselves and with the instructors, availability of grants/rewards, students' perceptions regarding the adoption of the flipped classroom, instructors' compatibility, and professional security.

Moreover, they were also asked if they thought any of the factors should be removed, and the majority of participants agreed that the factors covered the different aspects which may influence instructors' intentions to adopt the flipped classroom approach in their teaching.

\section{CONCLUSION AND FUTURE WORK}

This paper investigated certain factors with flipped classroom practitioners from computer science and related disciplines in order to confirm the proposed model. The responses provided insights into the significance of each factor of the proposed model from different perspectives. There was general agreement with all five factors, particularly the first three. Furthermore, Table VII summarises the key insights and observations collected from 14 flipped classroom practitioners.

TABLE VII: SUMMARISES THE KEY INSIGHTS AND OBSERVATIONS THAT COLLECTED FROM 14 FLIPPED CLASSROOM PRACTITIONERS

\begin{tabular}{|l|l|}
\hline Main Factors / Sub theme & \# of Agreement \\
\hline - Performance Expectancy (PE) & $\mathbf{1 1}$ out of 14 \\
\hline Better teaching experience & $\mathbf{1 3}$ out of $\mathbf{1 4}$ \\
\hline Enhancing instructors' productivity and academic performance? \\
\hline - Effort Expectancy (EE) & \multicolumn{1}{|l|}{} \\
\hline Decreasing the amount of effort required for educational process \\
\hline $\begin{array}{l}\text { Monitoring out-of-class activities through the learning management } \\
\text { systems }\end{array}$ \\
\hline - Social Influence (SI) \\
\hline Reasons for implementing the flipped classroom 14 \\
\hline First adopter of the flipped classroom \\
\hline - Facilitating Condition (FC) \\
\hline University management and IT support \\
\hline - Technology Self-Efficacy (TSEF) \\
\hline Instructor's confidence in using technology effectively \\
\hline The role of technology self-efficacy in the student learning experience \\
\hline
\end{tabular}

During the interviews, additional factors were proposed by practitioners that they believed also play a role in instructors' intentions to adopt the flipped classroom, as listed in Section V. A further paper will discuss the proposed additional factors mentioned in Section V. In order to confirm the proposed factors and the proposed model, an additional quantitative study will be conducted to investigate the proposed factors after refining the model with computer science instructors.

\section{LIMITATIONS}

A limitation of this phase was the number of participants. This could be because there are relatively few experienced flipped classroom practitioners, or their workload discouraged participation.

\section{CONFLICT OF INTEREST}

The authors declare no conflict of interest.

\section{AUTHOR CONTRIBUTIONS}

Eman M. Bakheet conducted the research; analyzed the data, wrote the paper; Andrew M Gravell reviewed the work, all authors had approved the final version.

\section{ACKNOWLEDGMENT}

My sincere thanks for flipped classroom practitioners in Computer science, Mathematics, Chemistry, Educational Information Technology, and Medicine, who provided me with insights to their experience, in addition to valuable feedback and opinions in investigating and validating the proposed factors based on their appreciated experience. My sincere thanks for Saudi Electronic University for the sponsorship.

\section{REFERENCES}

[1] W. M. Jackman, "Switching from traditional to blended learning at university level: Students' and lecturers' experiences," International Journal of Learning, Teaching and Educational Research, vol. 17, p. 5, 2018.

[2] M. R. Sajid, A. F. Laheji, F. Abothenain, Y. Salam, D. Aljayar, and A. Obeidat, "Can blended learning and the flipped classroom improve student learning and satisfaction in Saudi Arabia?" International Journal of Medical Education, vol. 7, p. 281, 2016.

[3] K. Pollari-Malmi, J. Guerra, P. Brusilovsky, L. Malmi, and T. Sirkiä, "On the value of using an interactive electronic textbook in an introductory programming course," in Proc. the 17th Koli Calling Conference on Computing Education Research, 2017, pp. 168-172.

[4] Y. Yang, H. Wu, and J. Cao, "Smartlearn: Predicting learning performance and discovering smart learning strategies in flipped classroom," in Proc. 2016 International Conference on Orange Technologies, 2016, pp. 92-95.

[5] M. N. Giannakos, J. Krogstie, and N. Chrisochoides, "Reviewing the flipped classroom research: Reflections for computer science education," in Proc. the Computer Science Education Research Conference, 2014, pp. 23-29.

[6] D. Horton, M. Craig, J. Campbell, P. Gries, and D. Zingaro, "Comparing outcomes in inverted and traditional CS1," in Proc. the 2014 Conference on Innovation \& Technology in Computer Science Education, 2014, pp. 261-266.

[7] G. C. Gannod, J. E. Burge, and M. T. Helmick, "Using the inverted classroom to teach software engineering," in Proc. the 30th International Conference on Software engineering, 2008, pp. 777-786.

[8] S. M. B. S. Salim and A. B. Bakri, "Conceptual model of collaborative e-learning acceptance," in Proc. the 2017 IEEE Conference on e-Learning, e-Management and e-Services (IC3e), 2017, pp. 36-43.

[9] B. Šumak and A. Šorgo, "The acceptance and use of interactive whiteboards among teachers: Differences in UTAUT determinants 
between pre-and post-adopters," Computers in Human Behavior, vol. 64, pp. 602-620, 2016.

[10] T. Teo and J. Noyes, "Explaining the intention to use technology among pre-service teachers: A multi-group analysis of the unified theory of acceptance and use of technology," Interactive Learning Environments, vol. 22, no. 1, pp. 51-66, 2014.

[11] T. Long, J. Cummins, and M. Waugh, "Investigating the factors that influence higher education instructors' decisions to adopt a flipped classroom instructional model," British Journal of Educational Technology, 2018.

[12] B. Šumak, G. Polancic, and M. Hericko, "An empirical study of virtual learning environment adoption using UTAUT," in Proc. the Second International Conference on Mobile, Hybrid, and On-line Learning, pp. 17-22, 2010.

[13] E. M. Bakheet and A. M. Gravell, "Flipped classroom from computer science instructors' perspectives: A proposed model," in Proc. the 2019 8th International Conference on Educational and Information Technology, pp. 131-136, 2019.

[14] V. Venkatesh, M. G. Morris, G. B. Davis, and F. D. Davis, "User acceptance of information technology: Toward a unified view," MIS Ouarterly, pp. 425-478, 2003.

[15] H. Khechine, S. Lakhal, D. Pascot, and A. Bytha, "UTAUT model for blended learning: The role of gender and age in the intention to use webinars," Interdisciplinary Journal of E-Learning and Learning Objects, vol. 10, no. 1, pp. 33-52, 2014.

[16] P.-C. Lin, H.-K. Lu, and S.-C. Liu, "Towards an education behavioral intention model for e-learning Systems: An extension of UTAUT,' Journal of Theoretical \& Applied Information Technology, vol. 47, p. 3 2013.

[17] J. W. Creswell, Educational Research: Planning, Conducting, and Evaluating Quantitative and Qualitative Research, 4/e, Pearson Education, Inc, 2012.

[18] V. Braun and V. Clarke, "Using thematic analysis in psychology," Qualitative Research in Psychology, vol. 3, no. 2, pp. 77-101, 2006.
Copyright (C) 2020 by the authors. This is an open access article distributed under the Creative Commons Attribution License which permits unrestricted use, distribution, and reproduction in any medium, provided the original work is properly cited (CC BY 4.0)

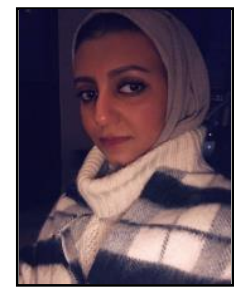

Eman Bakheet was born in Madinah, KSA. She studied bachelor of information systems at Taibah University, KSA, and master of information systems at Gannon University, USA. Currently she is a computer science $\mathrm{PhD}$ candidate at the University of Southampton, UK.

She was a lecturer at Saudi Electronic University, and was the branch coordinator for College of Computing. Her research interests are but not limited to, e-learning, technology enhanced learning, and

system analysis.

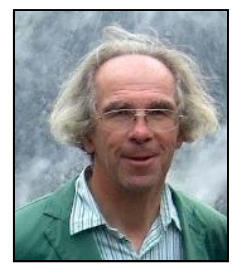

Andrew Gravell was born in 1956 in Exeter, UK. He studied math and computer science at Cambridge. He worked as a software developer for 7 years, mostly at IBM's Hursley Laboratory, working on a range of projects writing software for microprocessor-based systems.

In 1987 he joined ECS, Southampton, as a lecturer in computer science, and then as senior lecturer / associate professor / principal teaching fellow from 2002 onwards. He held the position of associate dean for Education and the Student Experience, Faculty of Physical and Applied Sciences from 2010 to 2015. His research interests are agile software development methods, computer science education and the computer science pipeline.

Dr. Gravell is an ECS senior tutor, timetabling owner, computer science teaching allocation, and chair of ECS Student Staff Liaison Committee. 